\title{
Explorations in Player Motivations: Virtual Agents
}

\author{
Barbaros Bostan \\ Interactive and Digital Media Institute (IDMI), National University of Singapore \\ idmbb@nus. edu.sg
}

\begin{abstract}
Creating believable agents with personality is a popular research area in game studies but academic research in this area usually focuses on one facet of personality - for example, only on moods or character traits. The present study proposes a motivational framework to predict goal-directed behaviour of virtual agents in a computer game and explores the opportunities of using personality inventories based on the same motivational framework to design virtual agents with personality. This article claims that motivation to reach a goal is influenced by psychological needs which are represented with an equation that determines the strength of a character's motivational force. The framework represented by this study takes into account psychological needs and their interrelations for analyzing choices of virtual agents in a computer game.
\end{abstract}

Keywords: Personality, motivations, virtual agents, behavioural architecture.

\section{Introduction}

Creating autonomous believable virtual agents is one of the primary concerns of game industry but today's digital entertainment industry uses different approaches to establish virtual characters that behave the most believable way. Previous studies indicate that virtual agents are more believable if they have their own personalities, emotions, goals, and motivations; if they are perceptive of environmental changes; if they keep track of their own social interactions (memories); and if they are capable of reacting to player choices and actions throughout the game $[1,2,3,4]$. However, there is still no integrated or universally accepted model of personality that can be applied to virtual agents of a computer game. Academic research in this area usually focuses on one facet of personality - for example, only on emotions or character traits. In this regard, this article aims to analyze the goal-directed behaviors and personality aspects of virtual agents by using a motivational framework that takes into account psychological needs, emotional states, moods or feelings, general behavioral patterns and personality traits. Assuming that goal-directed behavior is triggered by the interaction between personal and environmental factors, the proposed motivational variables are derived from basic human needs. The needs investigated with this framework are psychological in nature, are not static entities but the result of both internal and external forces, and are concerned with mental and emotional states of a person. 


\section{A Need Framework for Virtual Agents}

It is easy to understand the appeal of life-like virtual agents, but there is a great diversity of approaches on creating believable characters or characters with personality. To analyze the psychology of virtual characters, Paiva et al. [5] and Prada et al. [6] used emotional states and corresponding action tendencies; Lankoski et al. [7] used the the physiology-sociology-psychology three-dimensional structure with special emphasis on the protagonist of a story; Prada and Paiva [8] used the Five Factor Model of personality by focusing on extraversion and aggreeableness dimensions; Mosher \& Magerko [9] used the Five-Factor Model of personality to define personality templates; Tychsen et al. [10] used the Personal Attributes Questionnaire - PAQ [11] to examine the relationship between players and characters; Rizzo [12] analyzed believability of virtual characters from an emotional state perspective; Ravaja et al. [13] examined emotional response patterns and sense of presence with the help of mood states and the impulsive sensation seeking dimension of Zuckerman-Kuhlman Personality Questionnaire - ZKPQ [14]; Kshirsagar and Thalmann [15] and Romano and Wong [16] used the OCC Model of Emotions [17] to represent the personality of social characters; and other researchers attempted different combinations of emotions, personality traits, moods, beliefs, and desires $[18,19,20,21]$. This article does not claim that these studies are irrelevant with the psychology of virtual agents; however, because each one of them focuses on different personality aspects the proposed models are not compatible with eachother.

The proposed personality model of this article is based on the needs framework of Murray [22], which defines psychological needs by matching them with actions and feelings, appropriate desires and effects, emotions, personality traits, actones (motones and verbones), different forms of need activity (intravertive, subjectified, semiobjectified, egocentric, infravertive, etc.), pathology, social forms and common relationships with other needs such as fusions, conflicts, and subsidiations. Although several classifications of needs exist in literature, this study regards each need as an individual variable of personality and uses twenty-seven needs of Murray's study: Acquisition (nAcq), Construction (nCons), Order (nOrd), Retention (nRet), Aggression (nAgg), Blamavoidance (nBlam), Counteraction (nCnt), Defendance (nDfd), Deference (nDef), Dominance (nDom), Abasement (nAba), Affiliation (nAff), Nurturance (nNur), Rejection (nRej), Succorance (nSuc), Achievement (nAch), Autonomy (nAuto), Harmavoidance (nHarm), Infavoidance (nInf), Recognition (nRec), Exhibition (nExh), Cognizance (nCog), Exposition (nExp), Understanding (nUnd), Play (nPlay), Sentience (nSen), Sex (nSex).

A recent study focused on matching twenty-seven needs of this framework to common gaming situations in computer role-playing games (CRPGs) [23]. Variables defined by major motivational studies in literature $[24,25,26]$ are also matched by this study to corresponding psychological needs and/or components of goal-directed behaviour. In an attempt to take this study one step further and to identify the common interaction patterns between these individual needs, Bostan and Kaplancali [27] applied the same motivational framework to another computer game, analyzed psychological needs by defining the driving game mechanics behind them and identified common fusions of needs in the selected computer game (nAgg \& nHarm, nRet \& $n$ Acq, nAcq \& nDom, nCog \& nDom). The same authors also analyzed user-created 
content (mods) of a popular computer game within the same motivational framework in terms of the needs they satisfy [28]. It is shown that, although the restrictions imposed by the game mechanics significantly reduce the number of player needs satisfied by a game and trap the player within the common motivational cycle of Achievement, Aggression, Harmavoidance, and Acquisition [27], but game mods created by users attempt to compensate for this by satisfying the needs of Sentience, Exhibition, Recognition, Sex, Play and Affiliation [28].

\section{Predicting Virtual Agent Behaviour}

Goal-directed behavior is made up of the interactions occurring between individuals and their environments that triggers actions and virtual character's computational processes are driven by their goals and preferences. There are situational and personal factors that influence the motivation to reach a goal. This article does not aim to identify all of the personal determinants of human behaviour and focuses only on personal factors. It is concerned with the possibility of using motives of a virtual agent to predict the likelihood of their behaviours. In this regard, for each gaming situation (GS), one or more needs will be dominant, which will be referred as Primary Needs $(\mathrm{PN})$. Because some needs are in the service of others, whereas some others are opposing it, fusions of needs will be described with Secondary Needs (SN) and conflicting needs will be described with Opposing Needs (ON). For any gaming situation, the strength $\left(\mathrm{M}_{\mathrm{f}}\right)$ of the motivational force of a behavior $(\mathrm{B})$ is represented as $\mathrm{M}_{\mathrm{f}}(\mathrm{B} / \mathrm{GS})$ in Eq. 1. The strength of the motivational force is dependent on the personal factors (PN,SN,ON) that represent the personality of a virtual agent.

$$
\mathrm{M}_{\mathrm{f}}(\mathrm{B} / \mathrm{GS})=\sum \mathrm{PN}+\sum \mathrm{SN}-\sum \mathrm{ON}
$$

The variables of Eq. 1 should be better understood with a concrete gaming example but first we need character profiles that compose of psychological needs. If rapid prototyping techniques can be used to create virtual agents, cost and production time reduction will be a major advantage. In this regard, although it is possible to use the original study of Murray, there are personality inventories in literature (Personality Research Form: PRF, Edwards Personality Preference Schedule: EPPS and Adjective Check List: ACL) that are based on psychological needs. For example, to broaden the scope of information about the nature of needs, Jackson's Personality Research Form [29] presents different correlates. Using these correlations, it is possible to build a quick character profile according to vocations, such as architect, chemist, and pharmacist; interpersonal behaviors, such as generosity, leadership, and objectivity; human values, such as aesthetic, economic, and religious; personality aspects, such as anxiety, responsibility, and innovation; vocational interests, such as medical security, business, and sales; or character traits, such as ambition, extraversion, and trustfulness. For example, it is possible to come up with a quick profile for a male dominant leader (A) or a character of trustfulness (B). According to Jackson's Personality Research Form, virtual agent $\mathrm{A}$ is characterized by high Dominance and Exhibition, and and low Sentience and Understanding. Similarly, virtual agent B is 
characterized by high Abasement, Affiliation, Nurturance, and Succorance and low Aggression, Autonomy, and Defendance. Sample profiles of these characters derived from [29] are given blow:

Table 1. Sample Character Profiles

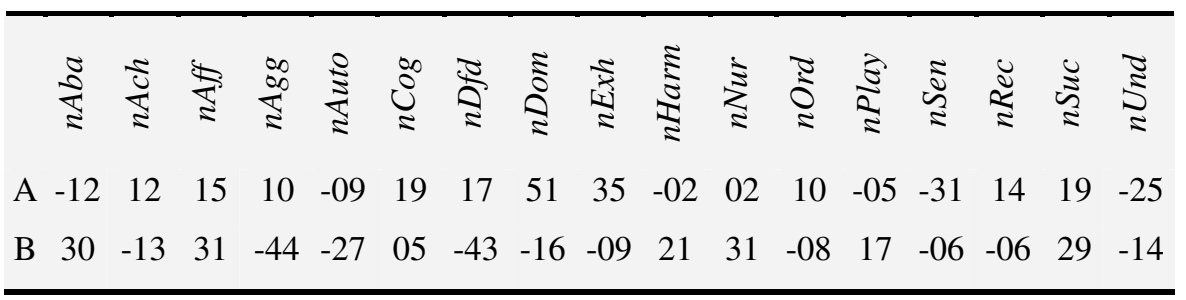

Assume that virtual agent $\mathrm{A}$ is the dominant military leader who faces a hostage situation, where a group of armed people took a number of hostages in a primary school. Not giving in to the demands of the villainous group, he orders the squad leader (virtual agent B) to raid the school and to eliminate any threats inside. When virtual agent $B$ expresses his reluctance by stating that little children may get harmed in the way and one of the children is a friend's son, but virtual agent A threats virtual agent $\mathrm{B}$ with his career for disobedience to a direct command. In this gaming situation, A is using "autocratic power", a fusion of Dominance and Aggression, whereas $\mathrm{B}$ is driven by his need to protect children (Nurturance), especially his friend's son (Affiliation), but his career (Achievement) is in danger if he disobeys the command. For this GS, it is possible to define different primary and secondary needs for different situations, but we assume that the primary need of A is Dominance whereas $A g$ gression is a secondary need and Nurturance is an opposing need. For virtual agent B, the PN is Nurturance, the SN is Affiliation and the ON is Achievement. Achievement is the opposing need of virtual agent B for this GS, but this character has a negative need for achievement which means that he does not care too much about his career. Thus, even if it is included in the equation as an ON, Achievement will behave like a $\mathrm{SN}$ for this GS. The motivational forces of each virtual agent are calculated below:

$$
\begin{aligned}
& \mathrm{M}_{\mathrm{fA}}(\mathrm{B} / \mathrm{GS})=\sum \mathrm{PN}+\sum \mathrm{SN}-\sum \mathrm{ON}=51+10-2=59 \\
& \mathrm{M}_{\mathrm{fB}}(\mathrm{B} / \mathrm{GS})=\sum \mathrm{PN}+\sum \mathrm{SN}-\sum \mathrm{ON}=31+31-(-13)=75
\end{aligned}
$$

The motivational forces of two virtual agents are opposing with each other but B's motivational force is stronger than A's. Thus, it is likely that B will disobey the command since the strength of the autocratic power employed by $\mathrm{A}$ is weaker than the combined motivational force of his psychological needs. But the important question is whether the secondary needs or the opposing needs are as important as the primary need. If the primary need is the dominant need for a psychological situation, the contributions of fusions and conflicts may be less influential on the total motivational force. A solution to this problem is to define the strength of the fusion or conflict, which will be represented with a multiplier of $\gamma$. Thus, for any gaming situation, the 
strength of the motivational force $\left(\mathrm{M}_{\mathrm{f}}\right)$ of a behavior (B) will now be represented as $\mathrm{M}_{\mathrm{f}}(\mathrm{B} / \mathrm{GS})$ in Eq. 2.

$$
\mathrm{M}_{\mathrm{f}}(\mathrm{B} / \mathrm{GS})=\sum \mathrm{PN}+\sum \gamma_{\mathrm{SN}} \cdot \mathrm{SN}-\sum \gamma_{\mathrm{ON}} \cdot \mathrm{ON}
$$

Assuming that the $\gamma$ values have a default value of 0.5 , the motivatonal forces of the two virtual agents for the GS in question are calculated again. Now B's motivational force is weaker than A's, which indicates an inclination towards obeying the order of virtual agent $\mathrm{A}$.

$$
\begin{aligned}
& \mathrm{M}_{\mathrm{fA}}(\mathrm{B} / \mathrm{GS})=\sum \mathrm{PN}+\sum \gamma_{\mathrm{SN}} \cdot \mathrm{SN}-\sum \gamma_{\mathrm{ON}} \cdot \mathrm{ON}=51+(0.5 * 10)-(0.5 * 2)=55 \\
& \mathrm{M}_{\mathrm{fB}}(\mathrm{B} / \mathrm{GS})=\sum \mathrm{PN}+\sum \gamma_{\mathrm{SN}} \cdot \mathrm{SN}-\sum \gamma_{\mathrm{ON}} . \mathrm{ON}=31+\left(0.5^{*} 31\right)-\left(0.5^{*}-13\right)=53
\end{aligned}
$$

The probability of the occurrence of a behavior can easily be calculated with the introduction of a random variable that represents the uncertainty in human behavior. Similar techniques can be found in table-top role playing games. For example, developed by Wizards of the Coast (formerly TSR), Advanced Dungeons and Dragons or $\mathrm{AD \& D}$ is a game of imagination, as well as a game of tactics and strategy, which has set the standard for role-playing for more than 30 years. The accumulated knowledge of table-top role playing games has also influenced the design of popular CRPGs which use rules or game mechanics based on their pen-and-paper equivalents. Indeed, the majority of the most successful computer role playing games (CRPGs) such as Baldur's Gate series ${ }^{1}$, Neverwinter Nights series ${ }^{2}$, Planescape Torment ${ }^{3}$, Icewind Dale series ${ }^{4}$, Knights of the Old Republic series ${ }^{5}$ and Fallout ${ }^{6}$ series, use AD\&D system or its variants. Understanding table-top role playing games and the mechanisms behind them can be useful in enhancing the quality of virtual agents. In this regard, these games have also drawn the attention of the researchers from the field of computer game studies $[30,31,32]$. These games represent randomness with dice rolls, for example $1 \mathrm{~d} 20$ for a dice roll between 1 and 20. Thus, the modified version of Eq. 2 with the addition of a random variable $(\mathrm{R})$ is given below:

$$
\mathrm{M}_{\mathrm{f}}(\mathrm{B} / \mathrm{GS})=\mathrm{R}+\sum \mathrm{PN}+\sum \gamma_{\mathrm{SN}} \cdot \mathrm{SN}-\sum \gamma_{\mathrm{ON}} \cdot \mathrm{ON}
$$

For example, assuming that the $\mathrm{R}$ value will have a $1 \%-20 \%$ contribution to motivational force, if virtual agent A rolls a 10 on a $1 \mathrm{~d} 20$ roll, the probability of the occurrence of a behavior can be calculated for virtual agent B. $\mathrm{M}_{\mathrm{fA}}$ totals up to 65 , and virtual agent $\mathrm{B}$ has to roll a 13 or better to oppose virtual agent B. So, there is only a $40 \%$ chance for virtual agent B to oppose the dominant leader's decision.

\footnotetext{
${ }^{1}$ Baldur's Gate (1998), Baldur's Gate II: Shadows of Amn (2000), both developed by Bioware.

${ }^{2}$ Neverwinter Nights (2002) developed by Bioware, Neverwinter Nights II (2006) developed by Obsidian Entertainment.

${ }^{3}$ Planescape Torment (1999) developed by Black Isle Studios.

${ }^{4}$ Icewind Dale (2000), Icewind Dale II (2002), both developed by Black Isle Studios.

${ }^{5}$ Knights of the Old Republic (2003) developed by Bioware, Knights of the Old Republic II: Sith Lords (2005) developed by Obsidian Entertainment.

${ }^{6}$ Fallout (1997), Fallout 2 (1998), both developed by Black Isle Studios, Fallout 3 (2008) developed by Bethesda Game Studios.
} 


\section{Conclusion}

This study proposes a motivational framework for analyzing virtual agent behaviour in computer games; defines an equation to predict the likelihood of the occurence of a behavior in different gaming situations; and utilizes personality inventories to rapidly design characters with personality. This article is unique in that the proposed motivational framework does not focus on static facets of personality but takes into account psychological needs and interactions between these needs. For each need, using the original study of Murray [22], it is possible to make connections with emotions, feelings, desires, general behavioral patterns, and personality traits. Combining psychological variables/findings of other studies on psychological needs, such as the Jackson's Personality Research Form [29], this study provides an extensive knowledge base for character design and rapid prototyping of virtual agents.

This article does not claim to have identified all the factors that affect human behaviour, but it does try to address how the proposed psychological needs should facilitate the prediction of virtual agent behaviour in computer games. The next challenge is to integrate situational factors such as goal valence and user expectancy into the proposed equations but the biggest challenge in developing this framework is to relate these needs with trait models of personality in literature, such as the Big Five Personality Traits. Relating the proposed needs with other personality aspects, such as emotions which have drawn the attention of AI researchers [33,34], and coordinating them with lower level sets of actions will provide a unified model of personality. The proposed need framework provides a solid foundation for future research in computer games by providing methods for designing virtual agents and assessing the motivational aspects of non-player characters. If the behavioural equation and the character profiles can be validated by future empirical studies, the framework defined in this study should significantly improve our understanding of virtual agent behaviour in computer games.

\section{References}

1. Cutumisu, M., Szafron, D., Schaeffer, J., Mcnaughton, M., Roy, T., Onuczko, C., Carbonaro, M.: Generating ambient behaviors in computer role-playing games. IEEE Intelligent Systems 21(5), 19-27 (2006)

2. Livingstone, D.: Turing's test and believable AI in games. ACM Computers in Entertainment 4(1), 6-18 (2006)

3. Romano, D.M., Wong, A.K.L.: Personality model of a social character. In: 18th British HCI Group Annual Conference (2004)

4. Kline, C., Blumberg, B.: The art and science of synthetic character design. In: Proceedings of the Symposium on AI and Creativity in Entertainment and Visual Art, AISB (1999)

5. Paiva, A., Dias, J., Sobral, D., Silva, C., Aylett, R.S., Woods, S., Zoll, C.: Caring for Agents and Agents that Care: Building Empathic Relations with Synthetic Agents. In: Proceedings of the Third International Joint Conference on Autonomous Agents and Multi Agent Systems, AAMAS 2004 (2004)

6. Prada, R., Vala, M., Paiva, A., Hook, K., Bullock, A.: FantasyA - The Duel of Emotions. Short paper at Intelligent Virtual Agents (IVA), Kloster Irsee, Germany (2003) 
7. Lankoski, P., Heliö, S., Ekman, I.: Characters in Computer Games: Toward Understanding Interpretation and Design. In: Proceedings of Level Up: Digital Games Research Conference (2003)

8. Prada, R., Paiva, A.: Believable groups of synthetic characters. In: Proceedings of the Fourth International Joint Conference on Autonomous Agents and Multi-Agent Systems (AAMAS 2005), pp. 37-43 (2005)

9. Mosher, R., Magerko, B.: Personality Templates and Social Hierarchies Using Stereotypes. In: Göbel, S., Malkewitz, R., Iurgel, I. (eds.) TIDSE 2006. LNCS, vol. 4326, pp. 207-218. Springer, Heidelberg (2006)

10. Tychsen, A., McIlwain, D., Brolund, T., Hitchens, M.: Player-Character Dynamics in Multi-Player Role Playing Games. In: Proceedings of DIGRA 2007, Tokyo, Japan (2007)

11. Spence, J., Helmreich, R., Holahan, C.: The Personal Attributes Questionnaire: A measure of sex role stereotypes and masculinity-feminity. Catalog of Selected Documents in Psychology 4, 43-44 (1974)

12. Rizzo, P.: Why Should Agents Be Emotional for Entertaining Users? A Critical Analysis. In: Paiva, A.C.R. (ed.) IWAI 1999. LNCS, vol. 1814, pp. 166-181. Springer, Heidelberg (2000)

13. Ravaja, N., Saari, T., Salminen, M., Laarni, J., Holopainen, J., Järvinen, A.: Emotional response patterns and sense of presence during video games: Potential criterion variables for game design. In: Proceedings of NordCHI 2004, Tampere, Finland (2004)

14. Zuckerman, M., Kuhlman, M., Joiremann, J., Teta, P., Kraft, M.: A Comparison of Three Structural Models for Personality: The Big Three, The Big Five, and the Alternative Five. Journal of Personality and Social Psychology 65, 757-768 (1993)

15. Kshirsagar, S., Thalmann, N.M.: Virtual Humans Personified. In: Proceedings of the first international joint conference on Autonomous Agents and Multi Agent Systems, AAMAS $2002(2002)$

16. Romano, D.M., Wong, A.K.L.: Personality Model of a Social Character. In: 18th British HCI Group Annual Conference, Leeds Metropolitan University, UK (2004)

17. Ortony, A., Clore, G., Collins, A.: The Cognitive Structure of Emotions. Cambridge University Press, Cambridge (1988)

18. Bailey, C., Katchabaw, M.: An emergent framework for realistic psychosocial behaviour in non player characters. In: Proceedings of the 2008 Conference on Future Play: Research, Play, Share, Ontario, Canada (2008)

19. Dugdale, J., El Jed, M., Pallamin, N., Pavard, B.: Modelling Character Emotion in an Interactive Virtual Environment. In: AISB Symposioum, Leeds, UK (2004)

20. Sandercock, J., Padgham, L., Zambetta, F.: Creating Adaptive and Individual Personalities in Many Characters Without Hand-Crafting Behaviors. In: Gratch, J., Young, M., Aylett, R.S., Ballin, D., Olivier, P. (eds.) IVA 2006. LNCS (LNAI), vol. 4133, pp. 357-368. Springer, Heidelberg (2006)

21. Masuch, M., Hartmann, K., Schuster, G.: Emotional Agents for Interactive Environments. In: Proceedings of 4th Int. Conf. on Creating, Connecting and Collaborating through Computing, University of California, Berkeley (2006)

22. Murray, H.A.: Explorations in personality. Oxford University Press, New York (1938)

23. Bostan, B.: Player Motivations: A Psychological Perspective. ACM Computers in Entertainment 7(2) (2009)

24. Sweetser, P., Wyeth, P.: GameFlow: A model for evaluating player enjoyment in games. ACM Computers in Entertainment 3(3), 1-24 (2005)

25. Malone, T.W., Lepper, M.R.: Making learning fun: A taxonomy of intrinsic motivations for learning. In: Snow, R.E., Farr, M.J. (eds.) Aptitude, Learning, and instruction: Conative and Affective Process Analyses. Lawrence Erlbaum, Hillsdale (1987) 
26. Yee, N.: Motivations of Play in Online Games. CyberPsychology \& Behavior 9(6), 772 775 (2006)

27. Bostan, B., Kaplancali, U.: Explorations in Player Motivations: Game Mechanics. In: Proceedings of GAMEON 2009, Düsseldorf, Germany (2009)

28. Bostan, B., Kaplancali, U.: Explorations in Player Motivations: Game Mods. In: Proceedings of GAMEON-ASIA 2010, Shanghai, China (2010)

29. Jackson, D.N.: Personality Research Form Manual. Research Psychologists Press, Port Huron (1989)

30. Tychsen, A., Hitchens, M., Brolund, T., Kavakli, M.: The Game Master. In: Proceedings of the Interactive Entertainment Conference, Sydney, Australia, pp. 215-222 (2005)

31. Peinado, F., Gervas, P.: Transferring game mastering laws to interactive digital storytelling. In: Göbel, S., Spierling, U., Hoffmann, A., Iurgel, I., Schneider, O., Dechau, J., Feix, A. (eds.) TIDSE 2004. LNCS, vol. 3105, pp. 1-12. Springer, Heidelberg (2004)

32. Louchart, S., Aylett, R.: Towards a narrative theory of virtual reality. Virtual Reality 7(1), 2-9 (2003)

33. Bosser, A., Levieux, G., Sehaba, K., Buendia, A., Corruble, V., Fondaumiere, G.D.: Dialogs taking into account experience, emotions and personality. In: DIMEA, pp. 9-12 (2007)

34. Sehaba, K., Sabouret, N., Corruble, V.: An Emotional Model for Synthetic Characters with Personality. In: Proceedings of the 2nd international Conference on Affective Computing and intelligent interaction, Lisbon, Portugal (2007) 